\title{
The Relationship Between Workers' Safety Culture and Accidents, Near Accidents and Health Problems
}

\author{
Małgorzata Milczarek \\ Andrzej Najmiec \\ Central Institute for Labour Protection - National Research Institute, Warsaw, Poland
}

\begin{abstract}
One of the dimensions treated as part of a company's safety culture or climate is workers' attitudes towards risk and safety. In the present study these personal aspects are defined as workers' safety culture, which is understood as a way of acting focused on life and taking care of one's health. A questionnaire on safety culture was filled out by 200 employees of a metallurgical enterprise. Factor analysis was used to determine empirical scales of the questionnaire, whereas variance analysis was used to test hypotheses. The results confirmed the hypotheses that people who experienced accidents, dangerous situations, and - to a lesser extent-health problems had a lower level of safety culture. Nevertheless not all of the scales determined during factor analysis turned out to be significant as far as all kinds of those undesirable situations are concerned. Proposals for future studies are formulated in the conclusion.
\end{abstract}

workers' safety culture safety behaviour accident prevention

\section{INTRODUCTION}

The conception of safety culture has existed in the literature for almost 20 years. According to Kuhlman [1] the increasing interest in safety culture is a result of changes characteristic for highly developed industrial societies. More importance is attached to the issues of equality, freedom of speech, and also of safety and taking care of one's health. Risk is not understood as an act of fate or destiny any more. Nowadays risk is considered in the context of human responsibility and actions taken by people [2]. Douglas and Wildavsky [3] say "risk-assessment techniques are the expert answer to the question of how much wealth should be sacrificed for how much health" (p. 67). Thus sometimes we can be faced with the dilemma whether, for example, the benefits resulting from new technology, which makes our lives more comfortable, compensate for the new risks created by that technology.

The level of safety culture is a result of the value of human life and health in a given society. Authors interested in creating and maintaining a strong safety culture refer to the culture determinants of accepting and taking risk in accordance with the assumption that effective and durable changes have to embrace the fundamental level of human functioning. Theoretical considerations on acceptable levels of risk and safety culture often concern whole societies. However research in this field is carried out in the work environment, usually in enterprises that create serious risks for workers or for the environment. Many studies have been based on Zohar's [4] conception of safety climate in a company. In the literature there are also a few theoretical models of safety culture, for example, [5] and [6].

Correspondence and requests for offprints should be sent to Małgorzata Milczarek, Central Institute for Labour Protection - National Research Institute, ul. Czerniakowska 16, 00-701 Warszawa, Poland. E-mail: <mamil@ciop.pl>. 
Although many authors stress the popularity of the conception of safety culture and its practical importance, there are a lot of ambiguities concerning safety culture especially in terms of the definition and the dimensions of this notion. Guldenmund [7] quotes several definitions of safety culture and climate. The fact there is a great variety of definitions seems to, at least to some extent, result from the very wide and interdisciplinary character of the notion of culture, which embraces aspects of psychology, sociology and anthropology. Nevertheless research results encourage further studies. It has been stated, among others, that enterprises with a good safety culture have lower accident rates than enterprises with a weak safety culture [8]. A negative relationship between a company's safety climate and workers' risk behaviours or accident rates has also been shown $[4,9,10,11,12,13]$.

One of the dimensions considered part of a company's safety culture or climate is workers' attitudes towards risk and safety. However, these individual variables are defined in various ways: workers' commitment to safety [14], motivation for safety behaviours, justification for taking risk, fatalism or optimism when dealing with safety [15], attitude towards safety [9] or personal commitment to safety [16]. Thus, many researchers have stressed an individual's attitude towards risk or safety as an inherent aspect of the safety culture characteristic for a given group of people. In the present study these personal aspects are defined as workers' safety culture.

\section{AIMS}

Workers' safety culture is understood as a way of acting focused on life and health care, which is the result of internalized norms, beliefs and values related to risk and safety. This is a new proposal; we have not come across any studies on workers' safety culture. As it was mentioned earlier most research has focused on the organizational level.

The aim of the present study was to explore the relationship between workers' safety culture and accidents, dangerous situations and health problems.
The conception of workers' safety culture is based on Pidgeon's conception of safety culture [17]. Pidgeon distinguished three main aspects of safety culture: (a) norms and rules for handling hazards which define what is and is not a significant risk and what response is appropriate, (b) attitudes towards safety which refers to individual and collective beliefs about hazards and the importance of safety and also motivation to act upon these beliefs, (c) reflexivity on safety practice as a learning process and searching for new meanings in the face of uncertainty and ambiguity about risk.

So "high" workers' safety culture seems to be associated with

- beliefs that different hazards influence human life and health and that correct behaviour can protect one from them;

- a high position of safety and health in one's system of values;

- considering the consequences of one's actions for one's own and other people's life and health;

- considering the influence of new and unknown hazards on one's life and health;

- internalized norms of behaviours related to safety regulations.

It has been assumed that workers' safety culture is associated with protecting one's life and health so it determines the level of safety of behaviours and also relates to pro-healthy behaviours. Accidents, dangerous situations and health problems have been assumed to be indicators of risk behaviours.

The following hypotheses have been formulated:

1. People who have experienced an accident at work will have a lower level of safety culture in comparison with people who have not experienced an accident at work.

2. People who have experienced a traffic accident, an accident at home or in other situations will have a lower level of safety culture in comparison with people who have not experienced such accidents. 
3. People who have experienced dangerous situations at work and outside work will have a lower level of safety culture than people who have not experienced such situations.

A hypothesis concerning health problems has also been formulated:

4. People who have experienced serious health problems associated or not associated with work will have a lower level of safety culture than people who have not experienced such problems.

\section{METHODS}

\subsection{Questionnaire on Workers' Safety Culture}

A special questionnaire to assess workers' safety culture was developed. The items were formulated with the theoretical assumptions described earlier. They are related to health and safety aspects: behaviours (e.g., My behaviour during leisure activities is usually careful and safe), beliefs (e.g., Good drivers know when they can break traffic regulations) and values (e.g., I want to enjoy life even if my health suffers as a result). The initial version of the questionnaire consisted of 30 items assess on a 5 -point scale ( $I$ strongly disagree, I disagree, It is hard to say, I agree, I strongly agree).

Preliminary research was carried out on 150 workers of a water-supply enterprise. The analysis showed the necessity to modify the questionnaire. The five items which had low correlation $(<.1)$ with the whole scale were rejected (e.g., I am as prone to accidents as others). There were also three items rejected because most people strongly agreed with them (e.g., When taking risk I can hurt somebody) and one which seemed to be unclear (When taking risk I put myself only in danger). The reliability of the scale (Cronbach's alpha), after nine items were rejected, was .83 . Nevertheless three items, with a similar meaning to those rejected, were added. Eventually a 24-item questionnaire was prepared.

\subsection{Experienced Accidents and Health Problems}

Ten questions on accidents experienced by participants in the past 3 years were added to the questionnaire. There were questions about accidents at work (which resulted in absence from work longer than 10 days, shorter than 10 days, shorter than 1 day and injuries), traffic accidents, accidents at home and in "other situations", dangerous situations at and outside work as well as health problems related or not related to work. Answers were given on a 3-point scale: no, yes or several times.

\subsection{Procedure}

Research was carried out in September 2002 in a metallurgical enterprise with about 1,000 employees. The questionnaires were distributed to workers by an occupational safety and health (OSH) specialist. Each participant was asked to fill in safety culture and accident questionnaires, which were provided in a special envelope. The filled out questionnaires were put back into the envelope, sealed, and left in a prearranged place. The authors of this study used that procedure to guarantee participants' anonymity and to encourage them to be honest.

\subsection{Participants}

Although research was anonymous there were questions about gender, age, position in the company and tenure.

The questionnaires were filled out by 200 employees, 197 of the correctly filled ones were analysed. Seventy-three percent of the participants were workers, $21 \%$ supervisors and $6 \%$ management. There were $14 \%$ female and $86 \%$ male participants. The average age of the respondents was 41 , and the average tenure with the organization was 18 years.

\subsection{Statistical Analysis}

Factor analysis was used to determine empirical scales of the workers' safety culture questionnaire, and variance analysis to test the hypotheses (SPSS software was used). 


\section{RESULTS}

\subsection{Results of Factor Analysis}

The questionnaire was analyzed using principal-components factor analysis with varimax rotation. Three factors were distinguished with initial eigenvalues over 1 , which explained $40 \%$ of variance. The reliability (Cronbach's alpha) for the whole scale was .89. The interpretation of the content as well as the reliability of each empirical scale (Factors I, II and III) are presented in Table 1.
Factor I explained $14 \%$ of variance, Cronbach's alpha $=.80$. The six items connected with this factor were interpreted as safety as a value. Table 1 shows the items and their correlations with the whole scale of workers' safety culture and the empirical scale.

Factor II explained $14 \%$ of variance, Cronbach's alpha $=.73$. The 11 items connected with this factor were interpreted as reflexivity on risk and safety behaviours. Table 2 shows the

TABLE 1. Items Connected With Factor I and Their Correlation With the Whole Scale of Workers' Safety Culture and the Empirical Scale

\begin{tabular}{lcc}
\hline Item & $\begin{array}{c}\text { Item and Whole } \\
\text { Scale Correlation }\end{array}$ & $\begin{array}{c}\text { Item and Factor I } \\
\text { Correlation }\end{array}$ \\
\hline I want to enjoy life even if my health suffers as a result. & .58 & .50 \\
I want my life to be interesting rather than safe. & .59 & .57 \\
$\begin{array}{l}\text { There are other things often more important for me than my } \\
\text { own safety. }\end{array}$ & .66 & .65 \\
$\begin{array}{l}\text { I comply with safety regulations only when I know that not } \\
\quad \text { doing so can lead to bearing consequences. }\end{array}$ & .47 & .51 \\
$\begin{array}{l}\text { I live "here and now" and I don't worry about the consequences } \\
\text { of my actions for my health in the future. }\end{array}$ & .63 & .61 \\
\begin{tabular}{l} 
I have too many problems to worry about my health. \\
\hline
\end{tabular} & .54 & .53 \\
\hline
\end{tabular}

TABLE 2. Items Connected With Factor II and Their Correlation With the Whole Scale of Workers' Safety Culture and the Empirical Scale

\begin{tabular}{|c|c|c|}
\hline Item & $\begin{array}{l}\text { Item and Whole } \\
\text { Scale Correlation }\end{array}$ & $\begin{array}{l}\text { Item and Factor II } \\
\text { Correlation }\end{array}$ \\
\hline $\begin{array}{l}\text { I consider the relationship between my lifestyle and nutrition } \\
\text { and my health. }\end{array}$ & .32 & .31 \\
\hline $\begin{array}{l}\text { I don't give up something I would like to do very much even it is } \\
\text { dangerous for my health. }\end{array}$ & .53 & .43 \\
\hline $\begin{array}{l}\text { Working conditions were important when I was looking } \\
\text { for work. }\end{array}$ & .36 & .36 \\
\hline I always have periodic medical examinations on time. & .30 & .29 \\
\hline $\begin{array}{l}\text { Regardless of lifestyle some people are ill and have accidents } \\
\text { whereas others don't. }\end{array}$ & .34 & .31 \\
\hline $\begin{array}{l}\text { I don't repeat behaviours which are dangerous for my life or } \\
\text { health (e.g., I have given up some stimulants) }\end{array}$ & .35 & .32 \\
\hline I think about my health even when I am healthy. & .45 & .49 \\
\hline $\begin{array}{l}\text { I would not accept work harmful to my health even if it was well } \\
\text { paid. }\end{array}$ & .32 & .29 \\
\hline $\begin{array}{l}\text { I am interested in information on how new technology and } \\
\text { devices affect my health. }\end{array}$ & .58 & .59 \\
\hline $\begin{array}{l}\text { My behaviour is usually careful and safe during leisure } \\
\text { activities. }\end{array}$ & .57 & .55 \\
\hline $\begin{array}{l}\text { You need a lot of time and money to take care of your health } \\
\text { and safety properly. }\end{array}$ & .46 & .35 \\
\hline
\end{tabular}


items and their correlations with the whole scale of workers' safety culture and the empirical scale.

Factor III explained $11 \%$ of variance, Cronbach's alpha $=.74$. The seven items connected with this factor were interpreted as internalization of safety rules. Table 3 shows the items and their correlations with the whole scale of workers' safety culture and the empirical scale.

\subsection{Results of Variance Analysis}

There were relatively few people who chose yes when answering questions on different kinds of accidents at work. So only one variable was created, that is, "accident at work". Similarly, few people (one or two) chose several times. So participants were divided into two groups only (people who had experienced or who had not experienced an accident at work). These rules were applied to all questions on accidents, dangerous situations and health problems.

All the hypotheses were tested using variance analysis.

\subsubsection{Hypothesis 1}

An analysis of variance (Table 4) revealed differences between the "accident" group and the "no accident" group as far as work accidents were concerned. Safety culture was higher in the "no accident" group $(F=10.379 ; p<.001)$ and there were also significant differences as far as each empirical scale was concerned (Factor I: $F=8.336 ; p<.004 ;$ Factor II: $F=7.361 ; p<.007$; Factor III: $F=8.153 ; p<.005$ ).

TABLE 3. Items Connected With Factor III and Their Correlation With the Whole Scale of Workers' Safety Culture and the Empirical Scale

\begin{tabular}{|c|c|c|}
\hline Item & $\begin{array}{l}\text { Item and Whole } \\
\text { Scale Correlation }\end{array}$ & $\begin{array}{l}\text { Item and Factor III } \\
\text { Correlation }\end{array}$ \\
\hline $\begin{array}{l}\text { Regulations in public places are useless because nobody } \\
\text { reads them. }\end{array}$ & .45 & .47 \\
\hline It is not dangerous to use medicines after their expiry date. & .41 & .42 \\
\hline $\begin{array}{l}\text { I don't persuade anybody to have more healthy and safe } \\
\text { behaviours. }\end{array}$ & .38 & .43 \\
\hline $\begin{array}{l}\text { OSH rules are usually an unnecessary limitation, everybody } \\
\text { can assess whether a situation is safe or dangerous. }\end{array}$ & .54 & .49 \\
\hline Good drivers know when they can break traffic regulations. & .48 & .40 \\
\hline $\begin{array}{l}\text { OSH rules are useful because there are made by competent } \\
\text { people. }\end{array}$ & .48 & .50 \\
\hline $\begin{array}{l}\text { I try to convince my family and friends to give up dangerous } \\
\text { behaviours. }\end{array}$ & .57 & .52 \\
\hline
\end{tabular}

TABLE 4. Safety Culture of Participants Who Had and Who Had Not Experienced an Accident at Work in the Past 3 Years (Analysis of Variance)

\begin{tabular}{|c|c|c|c|c|c|}
\hline \multirow[b]{2}{*}{ Variable } & \multirow{2}{*}{$\begin{array}{l}\text { Accident at } \\
\text { Work }\end{array}$} & \multirow[b]{2}{*}{$\mathbf{N}$} & \multirow[b]{2}{*}{$M$} & \multicolumn{2}{|c|}{ ANOVA } \\
\hline & & & & $\boldsymbol{F}$ & Significance \\
\hline \multirow{2}{*}{ The whole scale of workers' safety culture } & No & 155 & 94.35 & \multirow{2}{*}{10.379} & \multirow{2}{*}{.001} \\
\hline & Yes & 42 & 86.76 & & \\
\hline \multirow{2}{*}{ Factor I: Safety as a value } & No & 155 & 24.48 & \multirow{2}{*}{8.336} & \multirow{2}{*}{.004} \\
\hline & Yes & 42 & 22.21 & & \\
\hline \multirow{2}{*}{$\begin{array}{l}\text { Factor II: Reflexivity on risk and safety } \\
\text { behaviours }\end{array}$} & No & 155 & 41.42 & \multirow{2}{*}{7.361} & \multirow{2}{*}{.007} \\
\hline & Yes & 42 & 38.48 & & \\
\hline \multirow{2}{*}{ Factor III: Internalization of safety rules } & No & 155 & 24.22 & \multirow{2}{*}{8.153} & \multirow{2}{*}{.005} \\
\hline & Yes & 42 & 22.17 & & \\
\hline
\end{tabular}




\subsubsection{Hypothesis 2}

Safety culture of the "traffic accident" group was lower than of the "no accident" group $(F=8.063$; $p<.005)$. Significant differences were also observed for Factor I $(F=11.656 ; p<.001)$ and Factor III $(F=7.313 ; p<.007)$. Only a tendency was observed for Factor II (Table 5). differences for each empirical scale (Factor I: $F=12.183 ; p<.001 ;$ Factor II: $F=12.235$; $p<.001$; Factor III: $F=5.999 ; p<.015)($ Table 7).

\subsubsection{Hypothesis 3}

Regarding dangerous situations at work and outside work, people who had experienced such situations

TABLE 5. Safety Culture of Participants Who Had and Who Had Not Experienced an Accident in the Past 3 Years (Analysis of Variance)

\begin{tabular}{|c|c|c|c|c|c|}
\hline \multirow[b]{2}{*}{ Variable } & \multirow{2}{*}{$\begin{array}{c}\text { Traffic } \\
\text { Accident }\end{array}$} & \multirow[b]{2}{*}{$N$} & \multirow[b]{2}{*}{$M$} & \multicolumn{2}{|c|}{ ANOVA } \\
\hline & & & & $\boldsymbol{F}$ & Significance \\
\hline \multirow{2}{*}{ The whole scale of workers' safety culture } & No & 169 & 93.85 & \multirow{2}{*}{8.063} & \multirow{2}{*}{.005} \\
\hline & Yes & 28 & 88.57 & & \\
\hline \multirow{2}{*}{ Factor I: Safety as a value } & No & 169 & 24.44 & \multirow{2}{*}{11.656} & \multirow{2}{*}{.001} \\
\hline & Yes & 28 & 21.32 & & \\
\hline \multirow{2}{*}{$\begin{array}{l}\text { Factor II: Reflexivity on risk and safety } \\
\text { behaviours }\end{array}$} & No & 169 & 41.11 & \multirow{2}{*}{2.964} & \multirow{2}{*}{.087} \\
\hline & Yes & 28 & 38.89 & & \\
\hline \multirow{2}{*}{ Factor III: Internalization of the safety rules } & No & 169 & 24.11 & \multirow{2}{*}{7.313} & \multirow{2}{*}{.007} \\
\hline & Yes & 28 & 21.82 & & \\
\hline
\end{tabular}

TABLE 6. Safety Culture of Participants Who Had and Who Had Not Experienced an Accident at Home in the Past 3 Years (Analysis of Variance)

\begin{tabular}{lccccc}
\hline & Accident at & & & \multicolumn{2}{c}{ ANOVA } \\
\cline { 6 - 7 } Variable & Home & $\boldsymbol{N}$ & $\boldsymbol{M}$ & $\boldsymbol{F}$ & Significance \\
\hline \multirow{2}{*}{ The whole scale of workers' safety culture } & No & 170 & 93.49 & & \\
& Yes & 26 & 87.69 & 3.993 & .047 \\
Factor I: Safety as a value & No & 170 & 24.31 & & \\
Factor II: Reflexivity on risk and safety & Yes & 26 & 21.88 & 6.419 & .012 \\
behaviours & No & 170 & 40.98 & & \\
Factor III: Internalization of safety rules & Yes & 26 & 39.50 & 1.225 & .270 \\
& No & 170 & 24.04 & & \\
\hline
\end{tabular}

Safety culture of the "accident at home" group was lower than of the "no accident" group $(F=3.993 ; p<.047)$. Significant differences were also observed for Factor I $(F=6.419$; $p<.012)$ and Factor III $(F=4.241 ; p<.041)$. There was no significant difference for Factor II (Table 6).

As far as accidents in "other situations" are concerned, the "accident" group had a lower level of safety culture than the "no accident" group $(F=13.331 ; p<.000)$. There were also significant had a lower level of safety culture than people who had not experienced dangerous situations $(F=$ $6.281 ; p<.013)$. There were also significant differences for Factor I $(F=9.316 ; p<.003)$ and Factor II $(F=7.784 ; p<.006)$. There was no significant difference for Factor III (Table 8).

\subsubsection{Hypothesis 4}

Participants who had experienced in the past 3 years work-related health problems had a lower level of safety culture than participants who had not 
TABLE 7. Safety Culture of Participants Who Had and Who Had Not Experienced an Accident in "Other Situations" in the Past 3 Years (Analysis of Variance)

\begin{tabular}{|c|c|c|c|c|c|}
\hline \multirow[b]{2}{*}{ Variable } & \multirow{2}{*}{$\begin{array}{c}\text { Accident in } \\
\text { "Other } \\
\text { Situations" }\end{array}$} & \multirow[b]{2}{*}{$N$} & \multirow[b]{2}{*}{$M$} & \multicolumn{2}{|c|}{ ANOVA } \\
\hline & & & & $\boldsymbol{F}$ & Significance \\
\hline \multirow{2}{*}{ The whole scale of workers' safety culture } & No & 172 & 94.06 & \multirow{2}{*}{13.331} & \multirow{2}{*}{.000} \\
\hline & Yes & 25 & 83.56 & & \\
\hline \multirow{2}{*}{ Factor I: Safety as a value } & No & 172 & 24.42 & \multirow{2}{*}{12.183} & \multirow{2}{*}{.001} \\
\hline & Yes & 25 & 21.08 & & \\
\hline \multirow{2}{*}{$\begin{array}{l}\text { Factor II: Reflexivity on risk and safety } \\
\text { behaviours }\end{array}$} & No & 172 & 41.38 & \multirow{2}{*}{12.235} & \multirow{2}{*}{.001} \\
\hline & Yes & 25 & 36.76 & & \\
\hline \multirow{2}{*}{ Factor III: Internalization of safety rules } & No & 172 & 24.06 & \multirow{2}{*}{5.999} & \multirow{2}{*}{.015} \\
\hline & Yes & 25 & 21.88 & & \\
\hline
\end{tabular}

TABLE 8. Safety Culture of Participants Who Had and Who Had Not Experienced Dangerous Situations at Work and Outside Work in the Past 3 Years (Analysis of Variance)

\begin{tabular}{|c|c|c|c|c|c|}
\hline \multirow[b]{2}{*}{ Variable } & \multirow{2}{*}{$\begin{array}{l}\text { Dangerous } \\
\text { Situation at } \\
\text { Work and } \\
\text { Outside Work }\end{array}$} & \multirow[b]{2}{*}{$N$} & \multirow[b]{2}{*}{$M$} & \multicolumn{2}{|c|}{ ANOVA } \\
\hline & & & & $F$ & Significance \\
\hline \multirow{2}{*}{$\begin{array}{l}\text { The whole scale of workers' safety } \\
\text { culture }\end{array}$} & No & 125 & 94.58 & \multirow{2}{*}{6.281} & \multirow{2}{*}{.013} \\
\hline & Yes & 72 & 89.51 & & \\
\hline \multirow{2}{*}{ Factor I: Safety as a value } & No & 125 & 24.74 & \multirow{2}{*}{9.316} & \multirow{2}{*}{.003} \\
\hline & Yes & 72 & 22.71 & & \\
\hline \multirow{2}{*}{$\begin{array}{l}\text { Factor II: Reflexivity on risk and safety } \\
\text { behaviours }\end{array}$} & No & 125 & 41.74 & \multirow{2}{*}{7.784} & \multirow{2}{*}{.006} \\
\hline & Yes & 72 & 39.15 & & \\
\hline \multirow{2}{*}{ Factor III: Internalization of safety rules } & No & 125 & 23.92 & \multirow{2}{*}{.368} & \multirow{2}{*}{.545} \\
\hline & Yes & 72 & 23.54 & & \\
\hline
\end{tabular}

experienced such problems $(F=4.992 ; p<.027)$. Significant differences were also observed for Factor I $(F=6.466 ; p<.012)$ and Factor II $(F=4.700$; $p<.031)$. There was no difference for Factor III
(Table 9). As far as health problems not related with work are concerned, there were no significant differences between groups of people who had and who had not experienced such problems.

TABLE 9. Safety Culture of Participants Who Had and Who Had Not Experienced Work-Related Health Problems in the Past 3 Years (Analysis of Variance)

\begin{tabular}{|c|c|c|c|c|c|}
\hline \multirow[b]{2}{*}{ Variable } & \multirow{2}{*}{$\begin{array}{c}\text { Work-Related } \\
\text { Health } \\
\text { Problems }\end{array}$} & \multirow[b]{2}{*}{$N$} & \multirow[b]{2}{*}{$M$} & \multicolumn{2}{|c|}{ ANOVA } \\
\hline & & & & $\boldsymbol{F}$ & Significance \\
\hline \multirow{2}{*}{ The whole scale of workers' safety culture } & No & 166 & 93.67 & \multirow{2}{*}{4.992} & \multirow{2}{*}{.027} \\
\hline & Yes & 31 & 87.68 & & \\
\hline \multirow{2}{*}{ Factor I: Safety as a value } & No & 166 & 24.35 & \multirow{2}{*}{6.466} & \multirow{2}{*}{.012} \\
\hline & Yes & 31 & 22.10 & & \\
\hline \multirow{2}{*}{$\begin{array}{l}\text { Factor II: Reflexivity on risk and safety } \\
\text { behaviours }\end{array}$} & No & 166 & 41.22 & \multirow{2}{*}{4.700} & \multirow{2}{*}{.031} \\
\hline & Yes & 31 & 38.55 & & \\
\hline \multirow{2}{*}{ Factor III: Internalization of safety rules } & No & 166 & 23.94 & \multirow{2}{*}{1.492} & \multirow{2}{*}{.223} \\
\hline & Yes & 31 & 22.93 & & \\
\hline
\end{tabular}


Nevertheless a weak association was observed for Factor I $(F=2.917 ; p<.089)$, the "no experience of health problems" group had a higher level of safety culture.

\section{DISCUSSION}

The developed questionnaire on workers' safety culture had satisfying reliability for the whole safety culture scale and for each of the empirical scales (determined during factor analysis). Items connected with the empirical scales were interpreted as safety as a value (Factor I), reflexivity on risk and safety behaviours (Factor II) and internalization of safety rules (Factor III). So the whole scale of safety culture as well as the empirical scales could be used in the analysis. Nevertheless the stability of the empirical scales should be proved in future studies.

The results of variance analysis proved the hypothesis that people who had experienced accidents had a lower level of safety culture (they gained lower scores in the questionnaire used in this study). Nevertheless there were differences in the given kinds of accidents. Participants who had experienced an accident at work or in "other situations" had a lower level of safety culture, the differences were significant for the whole scale and for the three empirical scales. Participants who had experienced a traffic accident or an accident at home had a lower level of safety culture (the whole scale) and lower scores on the safety as a value (Factor I) and internalization of safety rules (Factor III) scales. The reflexivity on risk and safety behaviours (Factor II) scale was not significant. Participants who had experienced dangerous situations had a lower level of safety culture (the whole scale) and lower scores on the safety as a value (Factor I) and reflexivity on risk and safety behaviours (Factor II) scales. The internalization of safety rules (Factor III) scale was not significant.

For work-related health problems, there were significant differences only for the whole safety culture scale and the safety as a value (Factor I) scale (experienced health problems were associated with a lower lever of safety culture). There were no significant differences for health problems not related with work. Thus the results seem to suggest that there is no direct relationship between workers' safety culture and experienced health problems. It is possible that workers' safety culture defined in this study is connected with safety behaviours which result in accidents rather than with pro-health behaviours. Besides it seems that the relationship between pro-health behaviours and experienced health problems is more sophisticated and other factors (e.g., depression or family predispositions) should be considered, too.

\section{CONCLUSIONS}

In conclusion the conception of workers' safety culture and its relation to risk or safety behaviours seems to be justified. Workers' safety culture assessed with the questionnaire developed in this study turned out to be significantly associated with accidents, dangerous situations and, to a lesser extent, with health problems. Nevertheless not all the scales determined during factor analysis turned out to be significant for all kinds of those undesirable situations. Associations with the whole scale of safety culture and the safety as a value (Factor I) scale were strongest. However, accidents and health problems are only symptoms of some risk and unhealthy behaviours. The relationship between workers' safety culture and undesirable behaviours which unnecessarily result in accidents should be explored in a future study. It also seems that social and personal determinants of workers' safety culture should be subjects of further studies. This would make it possible to plan actions aimed at shaping high workers' safety culture and thus also high safety culture in organizations and societies. 


\section{REFERENCES}

1. Kuhlmann A. Safety culture. Köln, Germany: TÜV; 2001.

2. Lupton D. Risk and sociocultural theory. New directions and perspectives. Cambridge, UK: Cambridge University Press; 1999.

3. Douglas M, Wildavsky A. Risk and culture. An essay on the selection of technological and environmental dangers. Berkeley, CA, USA: University of California Press; 1982.

4. Zohar D. Safety climate in industrial organizations: theoretical and applied implications. J Appl Psychol 1980;65(1):96-102.

5. Cooper D. Towards a model of safety culture. Safety Science 2000;36(2):111-36.

6. Geller ES. The psychology of safety. Radnor, PA, USA: Chilton Book Company; 1996.

7. Guldenmund FW. The nature of safety culture: a review of theory and research. Safety Science 2000;34(1-3):215-57.

8. Horbury CR, Bottomley DM. Research into health and safety in the paper industry (IR/RAS/98/2) [unpublished document]. Health \& Safety Laboratory; 1998.

9. Cheyne A, Cox S, Oliver A, Tomas JM. Modelling safety climate in the prediction of levels of safety activity. Work Stress 1998;12(3):255-71.
10. Hayes B, Perander J, Smecko T, Trask J. Measuring perceptions of workplace safety: development and validation of the Work Safety Scale. J Safety Res 1998;29(3): 145-61.

11. Neal A, Griffin MA, Hart PM. The impact of organizational climate on safety climate and individual behavior. Safety Science 2000;34(1-3):99-109.

12. Ostvik J, Rundmo T, Sjoberg L. Associations between safety climate and emotional reactions to platform movements onboard an offshore installation. Safety Science 1997;26(3):155-68.

13. Zohar D. A group-level model of safety climate: testing the effect of group climate on microaccidents in manufacturing jobs. J Appl Psychol 2000;85(4):587-96.

14. Dedobbeleer N, Beland F. A safety climate measure for construction sites. J Safety Res 1991;22:97-103.

15. Williamson AM, Feyer AM, Cairns D, Biancotti D. The development of a measure of safety climate: the role of safety perceptions and attitudes. Safety Science 1997;25(1-3);15-27.

16. Cooper D. Improving safety culture. Chichester, UK: Wiley; 1998.

17. Pidgeon N. Safety culture and risk management in organizations. J Cross Cult Psychol 1991;22:129-40. 